\title{
Extracting the Expected Path of Monetary Policy from Futures Rates*
}

\author{
Brian Sack \\ Division of Monetary Affairs \\ Board of Governors of the Federal Reserve System \\ Washington, DC 20551
}

September 17, 2002

\footnotetext{
* The opinions expressed are those of the author and do not necessarily reflect the views of the Board of Governors or other members of its staff. I thank Jim Clouse, Lou Crandall, Benson Durham, Bill English, and Refet Gürkaynak for helpful comments. Correspondence can be directed to the above address, or to bsack@frb.gov.
} 


\title{
Extracting the Expected Path of Monetary Policy from Futures Rates
}

\begin{abstract}
Federal funds and eurodollar futures contracts are among the most useful instruments for deriving expectations of the future path of monetary policy. However, reading policy expectations from those instruments is complicated by the presence of risk premia. This paper demonstrates how to extract the expected policy path under the assumption that risk premia are constant over time, and under a simple model that allows risk premia to vary. In the latter case, the risk premia are identified under the assumption that policy expectations level out after a long enough horizon. The results provide evidence that the risk premia on these futures contracts vary over time. The impact of this variation is fairly limited for futures contracts with short horizons, but it increases as the horizon of the contracts lengthens.
\end{abstract}




\section{Introduction}

Federal funds and eurodollar futures contracts are among the most useful instruments available for deriving expectations about the path of monetary policy. These markets have impressive liquidity for contracts that span a range of horizons, and the values of the contracts are explicitly tied to realizations of short-term interest rates. Market participants often use these markets to hedge their exposures to changes in the level of short-term interest rates or simply to take positions on the direction of monetary policy. Indeed, market commentary on the valuation of these contracts is dominated by opinions about when the Federal Reserve's next policy action might take place and its direction and magnitude.

Besides being widely used by market participants for these purposes, academic researchers have also employed these futures contracts to measure market forecasts of the federal funds rate. ${ }^{1}$ Gürkaynak, Sack, and Swanson (2002) directly compare the predictive power of these futures rates to a number of other market-based measures of policy expectations. Their results indicate that federal funds futures dominate other market instruments at forecasting the federal funds rate over horizons out to several months, and that eurodollar futures perform marginally better than many other instruments at longer horizons. Thus, the practice of relying on these markets for policy expectations is empirically well supported.

This paper takes an in-depth look at how federal funds and eurodollar futures rates can be used to extract the expected future path of monetary policy. The primary

\footnotetext{
${ }^{1}$ Among other papers, Kruger and Kuttner (1996), Carlson, McIntire, and Thomson (1995), Robertson and Thornton (1997), and Söderström (2001) have used federal funds futures to predict monetary policy decisions, and Rudebusch (2002) and Jegadeesh and Pennacchi (1996) have used eurodollar futures. Lange, Sack, and Whitesell (2002) present evidence on the predictive power of both federal funds and eurodollar futures contracts.
} 
challenge in this process is accounting for the risk premia embedded in the futures rates. The analysis that follows begins by showing how to adjust for risk premia under the assumption that they are constant over time, as in many applications in the literature.

However, there is no reason to expect this assumption to hold, and thus the paper turns to an alternative approach that allows for some variation in the risk premia over time. The approach relies on a simple identification assumption that policy expectations level out beyond a horizon of several years. Under that assumption, differences between futures rates on contracts with long enough horizons will be driven primarily by their risk premia. These long-horizon futures rates can therefore be used to derive a proxy for a factor underlying movements in the risk premia on all futures contracts. The results provide evidence that the risk premia on these futures contracts do, in fact, vary over time. The impact of this variation is fairly limited for contracts with short horizons, but it increases as the horizon of the contracts lengthens. The analysis then demonstrates that portfolios of futures can be constructed to measure policy expectations that automatically account for this variation.

\section{The Information Content of Futures Rates}

Federal funds and eurodollar futures rates are directly influenced by the outlook for short-term interest rates. The value of a federal funds futures contract expiring $i$ months ahead is explicitly tied to the average of the effective overnight federal funds rate during the calendar month of expiration, $\overline{f f}(i)$, according to the formula $100-\overline{f f}(i){ }^{2}$

(All rates used here are measured in percentage points.) The value of a eurodollar futures

\footnotetext{
${ }^{2}$ The effective funds rate is converted to a daily series before averaging, so that observations on Fridays and before holidays carry additional weight.
} 
contract with an expiration $i$ quarters ahead is instead tied to the three-month Libor rate realized on the expiration date, $l i b(i)$, according to $100-l i b(i)$.

Given the ability of investors to substitute between a three-month eurodollar deposit and a strategy of rolling over loans in the overnight federal funds market, the Libor rate will be strongly influenced by the federal funds rate expected to prevail over the subsequent three months. Nevertheless, the linkage between those rates is not exact. Thus, it is useful to think of the payment on the eurodollar futures contract as having two components, $(100-\overline{f f}(i))-(\operatorname{lib}(i)-\overline{f f}(i))$. The first term in this payout is equivalent to that of federal funds futures, only where the average of the federal funds rate is taken over a three-month period starting at the expiration of the futures contract. ${ }^{3}$ The second term reflects "basis risk," or any differences that might arise between the Libor rate and the average federal funds rate.

The prices of federal funds and eurodollar futures contracts with expirations $i$ periods ahead, $P_{t}^{f f}(i)$ and $P_{t}^{e d}(i)$, respectively, are often converted to rates, which I denote $f u t_{t}^{f f}(i)$ and $f u t_{t}^{e d}(i)$, according to the formulas $P_{t}^{f f}(i)=100-f u t_{t}^{f f}(i)$ and $P_{t}^{e d}(i)=100-f u t_{t}^{e d}(i)$. These futures rates can be expressed as the sum of the expected future level of the underlying interest rate and a "risk premium," as follows:

$$
\begin{aligned}
& f u t_{t}^{f f}(i)=E_{t}[\overline{f f}(i)]+\rho_{t}^{f f}(i) \\
& f u t_{t}^{e d}(i)=E_{t}[l i b(i)]+\rho_{t}^{e d}(i) .
\end{aligned}
$$

\footnotetext{
${ }^{3}$ Actually, the eurodollar futures rate predicts the three-month return from rolling over overnight federal funds loans, and hence the daily federal funds rates should be compounded. This compounded return will approximately equal the average federal funds rate over the three-month period.
} 
The risk premia, $\rho_{t}^{f f}(i)$ and $\rho_{t}^{e d}(i)$, represent the expected excess return to an investor who is long the futures contract, which compensates the investor for the uncertainty associated with the return to taking that position. ${ }^{4}$

The equation for eurodollar futures must be modified to express the expectations in terms of the federal funds rate rather than the Libor rate, as follows:

$$
f u t_{t}^{e d}(i)=E_{t}[\overline{f f}(i)]+\rho_{t}^{l i b}(i)+\rho_{t}^{e d}(i),
$$

where the term $\rho_{t}^{l i b}(i)$ equals $E_{t}[l i b(i)-\bar{f}(i)]$. Thus, when expressed in terms of the expected federal funds rate, the eurodollar risk premium has an additional component $\rho_{t}^{l i b}(i)$ that equals the excess expected return of the three-month eurodollar deposit over the federal funds rate. This term will typically be positive, reflecting that investors face greater credit risk by lending to an institution for a three-month period rather than on an overnight basis. ${ }^{5}$

According to (1) and (3), the rates on federal funds and eurodollar futures can be used as proxies for expectations of the federal funds rate over different horizons, once one appropriately controls for the risk premia embedded in those rates. In that case, by using futures quotes covering different horizons, one could derive the entire path of the expected federal funds rate. To do so, I will use federal funds futures with expirations out to four months, and eurodollar futures with expirations out to five years. These markets are exceptionally liquid for federal funds futures expiring over the first several months and for eurodollar futures expiring over the next couple years. Eurodollar futures

\footnotetext{
${ }^{4}$ This paper refers to these terms as risk premia, but they actually encompass any factors resulting in an excess return on the contract, including institutional details, hedging activity, and liquidity considerations. Gürkaynak, Sack, and Swanson (2002) offer a more detailed discussion of the determination of risk premia. ${ }^{5}$ Note that there will also be a risk premium related to this basis risk, which is a component of the risk premium on the eurodollar futures contract, $\rho_{t}^{\text {ed }}(i)$.
} 
with longer horizons have less activity, but liquidity remains high enough to use those instruments for the purposes explained below. ${ }^{6}$

\section{Policy Expectations under Constant Risk Premia}

There exists a large literature on the predictive power of market interest rates that imposes the assumption that the risk premia embedded in those rates are constant over time - an assumption that is often referred to as the expectations hypothesis. Under that assumption, the expected path of the federal funds rate can be obtained by subtracting an estimate of the risk premia from the quoted futures rates.

To arrive at a measure of the risk premia embedded in these futures contracts, this paper relies on the information contained in the average shape of the term structure of futures rates. In doing so, I assume that expected changes in monetary policy have averaged to zero over the sample used, which runs from July 1992 to June 2002. This assumption seems reasonable, given that the policy instrument has remained in a relatively narrow range over the sample (making its average monthly change close to zero). Moreover, survey evidence roughly supports the assumption. According to a weekly survey performed by Money Market Services, the expected change in the federal funds rate over the subsequent three months averaged 2.63 basis points over our sample—less than one basis point per month. ${ }^{7}$

\footnotetext{
${ }^{6}$ Much of the trading activity in eurodollar futures contracts expiring beyond the next couple years is in the form of "bundles" and "packs," which are essentially blocks of contracts with consecutive expiration dates.

${ }^{7}$ The survey measure used was calculated by splicing together two data series: the expected federal funds rate six maintenance periods ahead to July 1997, and the expected federal funds rate two FOMC meetings ahead since then. The positive average expectation error suggests that the approach used may slightly overstate the average risk premium on near-term contracts.
} 
Under the assumption of zero average expectation errors, the average levels of federal funds and eurodollar futures rates relative to the average level of the overnight federal funds rate will reflect the risk premia on those contracts. ${ }^{8}$ Thus, this measure, which is shown in Figure 1 and reported in the first column of Table 1, is taken to be the estimate of the risk premia used in the analysis that follows. As can be seen, the risk premia on federal funds futures are very small. However, they have an upward slope of a couple of basis points per month, indicating that investors with long positions typically require a higher return on longer-horizon contracts because of the greater uncertainty associated with interest rate movements. The risk premia on eurodollar futures contracts start from a higher level than those on federal funds futures contracts and also increase as the horizon is extended, again likely reflecting the greater uncertainty associated with movements in three-month Libor over longer horizons. ${ }^{9}$

Under the assumption that these risk premia are time-invariant, one can derive the expected path of monetary policy simply by subtracting the estimated risk premia shown in Figure 1 from observed futures quotes. Some examples of the resulting paths for the federal funds rate are shown in Figure 2. In the figure, the rate implied by each contract is shown at the middle of the period covered by that contract. ${ }^{10}$ In March 2002, the intended federal funds rate was at 1.75 percent, and market participants anticipated that the FOMC would begin to gradually tighten monetary policy about two quarters ahead,

\footnotetext{
${ }^{8}$ An alternative approach for gauging the size of the risk premia is to use the average ex-post returns on futures contracts, as in Gürkaynak, Sack, and Swanson (2002). The idea is that expectation errors for the federal funds rate will average to zero over a long enough sample, so that the average ex-post returns will simply reflect the risk premia. Both that approach and the ex-ante approach used in the current paper are somewhat sensitive to the sample chosen, since the period of time for which data are available is not sufficiently long to ensure that expected policy changes or expectation errors average to zero.

${ }^{9}$ These patterns are similar to the ex-post measures reported in Gürkaynak, Sack, and Swanson (2002).

${ }^{10}$ In splicing together the rates implied by federal funds and eurodollar futures, I first plot the results from the federal funds futures over the current and following three months, and then those from eurodollar contracts expiring beyond then.
} 
with the federal funds rate expected to reach nearly 5 percent after several years. As indicated by the other dates shown in Figure 2, the expected policy path can take a variety of shapes. In early January 2001, market participants had priced in substantial easing over the subsequent year, although far less than was ultimately realized. And in May 1998, it appears that market participants expected policy to ease slowly over the subsequent two years.

\section{Evidence of Variation in Risk Premia}

The previous section demonstrates that it is straightforward to derive the expected path of monetary policy under the assumption of constant risk premia. Of course, there is no reason to believe that the risk premia on these futures contracts are constant over time. Indeed, this is likely not the case. In general, it is an empirical question as to whether the variation in the risk premia is large enough to significantly distort the policy expectations derived above. Unfortunately, it has proven difficult to derive useful measures of time varying risk premia.

This section presents some evidence on the extent to which risk premia vary over

time. The analysis first focuses on the behavior of the component $\rho^{l i b}(i)$, which again is the premium that investors demand to extend the horizon of a loan from overnight out to three months. Evidence on the behavior of this component can be obtained from quotes on basis swaps. Under these instruments, one party exchanges payments tied to the threemonth Libor rate (the rate underlying the eurodollar futures) in exchange for payments based on the average overnight federal funds rate over the subsequent three monthsprecisely the basis risk involved with eurodollar futures in the context discussed above. 
If basis swaps existed for a single future payment, an investor could create a "synthetic" federal funds futures contract by going long a eurodollar future and receiving Libor against federal funds in the basis swap. In fact, it can be shown that the spread on such a basis swap (the amount added to the federal funds payment in exchange for the Libor payment) is $\rho^{f f}(i)-\left(\rho^{l i b}(i)+\rho^{e d}(i)\right)$. Thus, a portfolio with a long position in a eurodollar future (equation (3)) combined with this basis swap has a return that is identical to the federal funds futures equation (1), only where the payout based on the three-month average of the federal funds rate rather than the one-month average.

This paper does not pursue the approach of systematically creating synthetic federal funds futures, given that the market for basis swaps is less liquid than that for futures and that most basis swaps involve a stream of payments rather than a single payment. ${ }^{11}$ Nonetheless, the swap quotes that are available provide useful information about the behavior of $\rho^{l i b}(i)$. As shown in Figure 3, basis swap spreads vary some over time, with the spreads increasing notably in the fall of 1998 and again in advance of Y2K. ${ }^{12}$ The figure also shows that the term structure of basis swap spreads is relatively flat—it typically has a slope of just a few basis points over five years. Thus, in the analysis that follows, I assume that this component of the risk premium changes over time but is independent of the horizon of the futures contract, or $\rho_{t}^{l i b}(i)=c_{t}$. The basis swap covering a one-year period has traded at an average spread of 21 basis points over the sample plotted, which I take as the average size of the component $\rho^{l i b}(i)$.

\footnotetext{
${ }^{11}$ Because most basis swaps involve a stream of quarterly payments, their use for hedging the basis risk of an individual futures contract is not clear-cut. One could smooth a yield curve through the basis swap quotes and construct basis swap forward rates to convert eurodollar futures into federal funds futures. ${ }^{12}$ Over the period leading up to Y2K, activity in the basis swap market was probably very light, and the spreads may have been influenced by idiosyncratic factors.
} 
Given that the component $\rho^{l i b}(i)$ is relatively flat across different contract horizons, the slope of the term structure of futures rates on any given day must instead reflect either monetary policy expectations or the other components of the risk premium, $\rho^{f f}(i)$ and $\rho^{e d}(i)$. Note that unlike $\rho^{l i b}(i)$, these other components of the risk premia will likely depend on the horizon of the contract, given that they measure compensation for bearing the risks arising from interest rate changes over that horizon. ${ }^{13}$

To separate these risk premia components from policy expectations, I rely on a simple identification assumption — that the expected path of monetary policy levels out within a horizon of four years. ${ }^{14}$ It seems unlikely that market participants formulate views about significant changes in the federal funds rate taking place four to five years ahead. By that time, the precision of their outlook is weak enough that their best guess is likely to be that the federal funds rate would be held steady (at a level that may shift around over time). If expectations for the federal funds rate level out after some horizon, differences in eurodollar futures rates for contracts expiring beyond that horizon will be influenced only by risk premia. Hence, the approach pursued in this paper is to derive an estimate of the behavior of these risk premia components based on the rates on futures contracts with long horizons.

This approach is best understood by looking at the term structure of eurodollar futures rates out to a five-year horizon for a recent date, shown in Figure 4. The rates on

\footnotetext{
${ }^{13}$ The risks underlying the premia $\rho^{f f}(i)$ and $\rho^{e d}(i)$ are slightly different, in that one is based on uncertainty surrounding movements in the federal funds rate and the other on uncertainty about movements in the three-month Libor rate. (The same point was raised earlier in footnote 5.) In the application below, I allow these contracts to have different factor loadings to account for this consideration.

${ }^{14}$ Some market participants may use a similar approach. Goldman Sachs (2001) reports using the slope of the eurodollar term structure from one to two years ahead to control for variation in the risk premium. That report also argues that it might have been better at that time to control for the risk premium using a more general measure of the steepness of the term structure, such as the slope from two to ten years ahead.
} 
near-term contracts are quite low, reflecting the accommodative stance of monetary policy at that time, and the rates rise considerably for contracts expiring in 2003 and 2004, in part reflecting the view that short-term interest rates will rise over that period. Beyond that horizon, the eurodollar curve continues to have an upward slope and becomes nearly linear for contracts expiring beyond 2004 (except for the slight elevation in every fourth contract, which reflects a year-end premium for contracts expiring each December). It turns out that the far end of the eurodollar futures term structure is almost always upward sloping. Obviously, it would be difficult to explain this pattern based on policy expectations - that is, by perennial expectations of policy tightening. Instead, I assume that this slope reflects the risk premia on those contracts - the basis for the identification approach taken here.

Under this interpretation, I take the difference between the futures rate expiring five years ahead and that expiring four years ahead as a proxy for the factor driving the components of the risk premium $\rho^{f f}(i)$ and $\rho^{e d}(i) .^{15}$ Figure 5 shows a time series of this slope factor, which I denote $s_{t}$, since the early $1990 \mathrm{~s}$, where the slope is expressed on a per-month basis. As is evident, the measure demonstrates considerable variation over time. It was at its widest in the early 1990s and narrowed considerably, on balance, into 1998. In the fall of 1998, it widened sharply before narrowing again (although it appeared elevated from Y2K concerns), and it then rose considerably over the past couple years.

Looking across all futures contracts, I assume that the components of the risk premium $\rho^{f f}(i)$ and $\rho^{e d}(i)$ are driven by a one-factor model in which they are linearly

\footnotetext{
${ }^{15}$ By using contracts expiring in the same calendar month, I avoid any distortions arising from the year-end premium, assuming that it is the same size in both years.
} 
related to the slope factor from Figure 5. The loadings of each contract on this factor are denoted by $\beta$, so that $\rho_{t}^{f f}(i)=\beta^{f f}(i) \cdot s_{t}$ and $\rho_{t}^{\text {ed }}(i)=\beta^{\text {ed }}(i) \cdot s_{t}$. Note that the loadings are time invariant but differ across the individual futures contracts. Thus, the model assumes that the risk premia for all futures contracts adjust over time proportionally to movements in the slope factor $s_{t}$.

The loadings of the individual contracts are determined so that the average level of the slope factor explains the average shape of the term structure of futures rates shown earlier in Figure $1 .{ }^{16}$ Of course, the eurodollar futures curve also embeds the other component of the risk premia, $\rho^{l i b}(i)$, which explains why it begins at a higher level, on average, than the federal funds futures curve. Thus, one must first subtract the average size of the component $\rho^{l i b}(i)$ (21 basis points) from the eurodollar futures curve. The factor loadings are then calculated by dividing the remaining average shape of the futures curves by the average level of the slope factor $s_{t}$, which imposes that the average shape of the futures curve is obtained when the slope factor is at its average level. ${ }^{17}$ Reflecting the shapes shown in Figure 1, the loadings increase more steeply for contracts with shorter horizons and then become quite linear at longer horizons. The loadings on the slope factor are reported in the second column of Table 1.

The next section explores how to derive the expected path of monetary policy when the risk premia on the futures contracts are time varying.

\footnotetext{
${ }^{16}$ A simpler version of the model assumes that the risk premium is linear in the time to expiration of the contract. In that case, the measures derived below simply adjust for the slope of the term structure in deriving policy expectations.

${ }^{17}$ Under this procedure, the loading on the contract expiring five years ahead, $\beta_{t}^{e d}(5 y)$, will equal $1+\beta_{t}^{e d}(4 y)$, so that the difference in the rates of those contracts will yield $s_{t}$.
} 


\section{Portfolios as Proxies for Policy Expectations}

The expected path of monetary policy under time-varying risk premia can be approximated by constructing simple portfolios of futures contracts. ${ }^{18}$ Under the structure of the risk premia assumed in the previous section, the rates on eurodollar futures contracts with expirations of four and five years (denoted $e d_{t}(4 y)$ and $\left.e d_{t}(5 y)\right)$ will be determined as follows:

$$
\begin{aligned}
& f u t_{t}^{e d}(4 y)=f f_{t}^{*}+c_{t}+\beta^{e d}(4 y) \cdot s_{t} \\
& f u t_{t}^{e d}(5 y)=f f_{t}^{*}+c_{t}+\left(1+\beta^{e d}(4 y)\right) \cdot s_{t},
\end{aligned}
$$

where the federal funds rate is assumed to return to its equilibrium level $f f_{t}^{*}$ within four years - the identification assumption used in the previous section.

In the analysis that follows, those two contracts are used to control for the time variation in the risk premium in any other futures contract. ${ }^{19}$ To see that, consider as an example the rate on the eurodollar futures contract expiring a year ahead, which is determined as follows:

$$
f u t_{t}^{e d}(1 y)=\overline{f f}(1 y)+c_{t}+\beta^{e d}(1 y) \cdot s_{t}
$$

where $\overline{f f}(1 y)$ is the expected average federal funds rate for the three months beginning a year ahead. By constructing portfolios of the three futures contracts (4) to (6), one can derive measures of policy expectations from the contract (6) that have been "cleansed" of

\footnotetext{
${ }^{18}$ An alternative approach is to formulate a model that contains additional structure, where the model's parameters (including time-varying risk premia) could be estimated across the entire term structure of futures rates. Such a model could incorporate additional details about the futures market, such as the existence of a year-end premium on December contracts. However, a disadvantage of the model approach is that it would presumably have to impose more structure on policy expectations.

${ }^{19}$ One cannot solve for all of the unknown variables or parameters - that is, $\overline{f f}, f f_{t}^{*}, c_{t}$, and $s_{t}$-in (4) through (6). In particular, the longer-term contracts cannot separate out $f f_{t}^{*}$ and $c_{t}$ separately. Thus, most of the portfolios constructed will measure expectations relative to one of those parameters.
} 
much of the time variation in the risk premium. I consider two different portfolio strategies.

First, consider a portfolio that is long one unit of $f u t_{t}^{e d}(1 y)$, long $\beta^{e d}(1 y)$ units of $f u t_{t}^{e d}(4 y)$, and short $\beta^{e d}(1 y)$ units of $f u t_{t}^{e d}(5 y)$. The basic idea of this portfolio is that being long $f u t_{t}^{e d}(4 y)$ and short $f u t_{t}^{e d}(5 y)$ gives the investor a net short position of $\beta^{e d}(1 y)$ units of the factor $s_{t}$, which hedges the exposure to that factor arising from holding $f u t_{t}^{e d}(1 y)$. Indeed, based on equations (4) to (6), the value of this portfolio is as follows:

$$
f u t_{t}^{e d}(1 y)+\beta^{e d}(1 y) \cdot f u t_{t}^{e d}(4 y)-\beta^{e d}(1 y) \cdot f u t_{t}^{e d}(1 y)=\overline{f f}(1 y)+c_{t} .
$$

As you can see, this portfolio therefore provides a reading of the expected federal funds rate that is immune to changes in the slope of the risk premia $s_{t}$, although it still includes the basis term $c_{t}$. Of course, other futures rates can be used to derive similar measures of expectations at other horizons.

The second portfolio strategy considered involves long positions of one unit of $f u t_{t}^{e d}(1 y)$ and $\left(\beta^{e d}(4 y)-\beta^{e d}(1 y)\right)$ units of $f u t_{t}^{e d}(5 y)$, and a short position of $\left(1+\beta^{e d}(4 y)-\right.$ $\left.\beta^{e d}(1 y)\right)$ units of $f u t_{t}^{e d}(4 y)$. The value of this portfolio is as follows:

$$
\begin{aligned}
& f u t_{t}^{e d}(1 y)-\left(1+\beta^{e d}(4 y)-\beta^{e d}(1 y)\right) \cdot f u t_{t}^{e d}(4 y)+\left(\beta^{e d}(4 y)-\beta^{e d}(1 y)\right) \cdot f u t_{t}^{e d}(5 y) \\
& =\overline{f f}(1 y)-f f_{t}^{*}
\end{aligned}
$$

As can be seen, this portfolio provides a reading of the expected deviation of the federal funds rate from its long-run level, or a measure of the stance of monetary policy. Note 
that this measure is immune to shifts in all components of the risk premium-both the basis term $c_{t}$ and the slope term $s_{t}$.

For federal funds futures, the information that results from these measures is slightly different, given that the futures rate does not contain the risk premium component $c_{t}$. The rate on a federal funds futures contract expiring three months ahead, for example, is given by

$$
f u t_{t}^{f f}(3 m)=\overline{f f}(3 m)+\beta^{f f}(3 m) \cdot s_{t},
$$

in which case the payout from portfolio strategy (7) becomes just $\overline{f f}(3 m)$, and that from strategy (8) becomes $\overline{f f}(3 m)-f f_{t}^{*}+c_{t}$. Thus, the distortion presented by $c_{t}$ shifts from one measure to the other.

The time series of measure (7) is shown for several horizons in Figure 6. In this figure and the ones that follow, I subtract the average level of $c_{t}$ (21 basis points) from the measure. ${ }^{20}$ The measure seems to correspond well with policy expectations, generally moving in advance of changes in the target federal funds rate. Moreover, expectations two years ahead often move by more than the year-ahead measure, in many cases reflecting expectations that the federal funds rate will continue to move in the same direction.

The impact of variation in the risk premia on the measurement of policy expectations can be sizable. Figure 7 repeats the policy expectations for two of the dates shown earlier in Figure 2, but now showing the estimate under the time-varying risk

\footnotetext{
${ }^{20}$ As discussed earlier, one could arrive at a time-varying estimate of $c_{t}$ based on basis swaps. Alternatively, one could estimate it from the difference between the spot Libor rate and a combination of federal funds futures expiring over the subsequent three months.
} 
premia as well. For the March 2002 observation, the difference in the paths is minimal, as the measured risk premium factor that day was only slightly above the average over the whole sample. The difference is more substantial in May 1998, when the risk premium factor was well below its average level over the sample (see Figure 5). Under the assumption that the risk premium is constant, one would subtract off too large of a risk premium, resulting in an expected policy path with more than a percentage point of easing over the subsequent three years. The smaller adjustment made under the timevarying risk premium model instead results in policy expectations that are largely flat, consistent with market commentary at that time. ${ }^{21}$

The second measure of policy expectations, equation (8), is shown in Figure 8. This measure appears to provide a plausible proxy for the expected stance of monetary policy. The period that is particularly notable from the graph is the accommodative stance of year-ahead policy expectations from mid-2001 to mid-2002, when the setting of the federal funds rate was viewed as being several percentage points below its long-run level. Interestingly, at the two-year horizon this measure is much more stable than the measure (7). This finding indicates that the long-run level of the expected federal funds rate, $f f_{t}^{*}$, is to a large extent adjusting in line with the expectation of policy two years ahead. Such behavior is somewhat puzzling, although it is consistent with the findings of

\footnotetext{
${ }^{21}$ Survey evidence indicates that market participants saw a small risk of policy tightening at that time. Indeed, a survey conducted by Money Market Services on May 1, 1998 indicated that market participants on average expected the federal funds rate to move from its level of 5.50 percent to a level of 5.51 percent at the subsequent FOMC meeting, 5.53 percent at the second meeting, and 5.59 percent at the third meeting.
} 
other parts of the empirical finance literature that longer-term forward rates are highly volatile. $^{22}$

In Figure 9, the stance of policy measure (8) is shown for all horizons on the three dates highlighted above. Consistent with the above discussion, the stance of policy was about 175 basis points below the anticipated long-run level of the federal funds rate in March 2002 and was expected to gradually move up to that level. In January 2001, policy was viewed as being 125 basis points above the long-run level and was expected to move most of the way to the long-run level within a year. Lastly, policy was viewed as being only marginally above the long-run level in May 1998.

\section{How Important is Time Variation?}

The above analysis presents evidence that risk premia on futures contracts are time varying. To determine how important this variation is, the standard deviations of daily changes in the identified risk premia are compared to those of the futures rates themselves in Figure 10. As is evident, the risk premium accounts for little of the variation in the futures rate for contracts with shorter horizons. As the horizon extends, though, the importance of the risk premium increases. In fact, it eventually surpasses the standard deviation of the futures rate, reflecting the negative covariance between the risk premium and expected policy at that horizon (an observation that is discussed more in the next section).

These results are consistent with the examples shown earlier in Figure 7, in which the adjustments to the policy paths were small at first but cumulated to larger amounts at

\footnotetext{
${ }^{22}$ The finding is consistent with the importance of the "level" factor in explaining yield curve movements, as pointed out by Litterman and Scheinkman (1991). The excess volatility of long-term rates has been discussed as far back as Shiller (1979).
} 
longer horizons. Overall, then, extracting policy expectations under the assumption of a constant risk premium may not be too misleading for shorter horizons. However, at longer horizons, variation in the risk premium is large enough that it must be taken into account to accurately measure the expected policy path embedded in futures rates.

\section{Caveats}

The approach described in this paper has the advantage of simplicity. The identification assumption is easy to understand, and the model can be "solved" by constructing some simple portfolios of futures contracts. However, that simplicity comes at some cost—primarily that the structure of the risk premium is determined using an ad-hoc procedure. One could instead use a model to derive the structure of the risk premium embedded in futures contracts, as in Jegadeesh and Pennacchi (1996). Such an approach has the advantage that the risk premium is derived from first principles.

However, that approach has the disadvantage that it must place considerable structure on the expected policy path, unlike the portfolio approach described above. ${ }^{23}$

The determination of the risk premium under the approach taken here involves some fairly strong assumptions. Among them, it is difficult to understand why the risk premium increases linearly at long horizons, especially considering that the interest rate is expected to have reached some long-run level. Nevertheless, the positive slope of the eurodollar futures curve at long horizons is an empirical regularity, and it seems even more implausible that this pattern can be attributed to policy expectations.

An important issue in this regard, however, is whether the horizon at which policy expectations are assumed to level out is sufficiently long. One observation that is

\footnotetext{
${ }^{23}$ For example, the interest rate must always revert to what they call the central tendency at the same speed.
} 
somewhat concerning in this regard is that the measured risk premium factor is negatively correlated with near-term futures rates. This correlation may indicate that the reversion of the short rate to its long-run level takes longer than the four years assumed. Indeed, this would be consistent with the results of Jegadeesh and Pennacchi (1996), who find that it takes over four years for the short rate to revert half way to its short-run tendency. ${ }^{24}$ However, an alternative interpretation is that the negative correlation arises for economic reasons: Periods of economic weakness tend to involve expectations of lower interest rates and higher risk premia.

One could address this issue directly by moving further out the term structure to derive the risk premium proxy. However, because the liquidity of futures contracts is fairly low at longer horizons, it would be advisable to derive the factor from the swaps curve in that case. I leave that exercise for future work.

\section{Conclusions}

Federal funds and eurodollar futures contracts are perhaps the most useful instruments for deriving the expected path of monetary policy from asset prices, given that their values are explicitly tied to short-term interest rates and that they have considerable liquidity over a wide range of horizons. However, the derivation of policy expectations is complicated by the presence of risk premia on those contracts. This paper demonstrates how to extract the expected path of policy under the assumption that the risk premia are constant over time, and under a simple model that allows the risk premia to vary. The results provide evidence that the risk premia on those contracts do, in fact, vary over time. The impact of this variation is

\footnotetext{
${ }^{24}$ However, their estimates of the central tendency in that paper do not seem very plausible.
} 
fairly limited for futures contracts with relatively short horizons, but it increases as the horizon of the contract lengthens.

In measuring the time-varying risk premia, the basic identification assumption employed is that policy expectations level out at some point in the future. Indeed, it seems unlikely that market participants hold strong views about Federal Reserve policy actions taking place four years ahead or longer, and hence contracts expiring at such horizons should provide valuable information about the risk premia embedded in futures rates. Of course, the analysis above is only one simple model of the behavior of the risk premia. Future research may be able to improve on the assumed structure of the risk premia, while retaining the basic approach to identification taken in this paper.

\section{References}

Carlson, John B., Jean M. McIntire, and James B. Thomson, "Federal Funds Futures as an Indicator of Future Monetary Policy: A Primer," Federal Reserve Bank of Cleveland Economic Review 31, 20-30.

Goldman Sachs (2001), “Message in the Market," Fixed Income Weekly Market Outlook, April 20, 2001.

Gürkaynak, Refet S., Brian Sack, and Eric Swanson (2002), "Market-Based Measures of Monetary Policy Expectations," Finance and Economics Discussion Series Working Paper \#2002-40, Board of Governors of the Federal Reserve System. 
Jegadeesh, Narasimhan and George G. Pennacchi (1996), “The Behavior of Interest Rates Implied by the Term Structure of Eurodollar Futures," Journal of Money, Credit, and Banking 28, 420-446.

Krueger, Joel T. and Kenneth N. Kuttner (1996), "The Fed Funds Futures Rate as a Predictor of Federal Reserve Policy," Journal of Futures Markets 16, 865-879.

Lange, Joe, Brian Sack, and William Whitesell (2002), "Anticipations of Monetary Policy in Financial Markets," forthcoming, Journal of Money, Credit, and Banking.

Litterman, R. and Scheinkman, J. (1991), "Common Factors Affecting Bond Returns," Journal of Fixed Income 1, 54-61.

Robertson, John C. and Daniel L. Thornton, "Using Federal Funds Futures to Predict Federal Reserve Actions," Federal Reserve Bank of St. Louis Review 78, 19-31.

Rudebusch, Glenn (2002), "Term Structure Evidence on Interest Rate Smoothing and Monetary Policy Inertia," forthcoming, Journal of Money, Credit, and Banking.

Shiller, Robert J. (1979), "The Volatility of Long-Term Interest Rates and Expectations Models of the Term Structure," Journal of Political Economy 87, 1190-1219.

Söderström, Ulf (2001), "Predicting Monetary Policy with Federal Funds Futures Prices," Journal of Futures Markets 21, 377-391. 
Table 1

\section{Estimated Risk Premia Levels and Loadings}

\begin{tabular}{|c|c|c|}
\hline Contract & $\begin{array}{c}\text { Constant Risk Premium } \\
\text { (Basis Points) }\end{array}$ & $\begin{array}{l}\text { Loading on Slope Factor } \\
\qquad\left(\beta^{f f}(i) \text { or } \beta^{e d}(i)\right)\end{array}$ \\
\hline \multicolumn{3}{|c|}{ Federal Funds Futures (months ahead) } \\
\hline 1 & 2 & 0.12 \\
\hline 2 & 4 & 0.22 \\
\hline 3 & 7 & 0.33 \\
\hline 4 & 10 & 0.48 \\
\hline \multicolumn{3}{|c|}{ Eurodollar Futures (quarters ahead) } \\
\hline 1 & 32 & 0.51 \\
\hline 2 & 46 & 1.21 \\
\hline 3 & 65 & 2.10 \\
\hline 4 & 85 & 3.06 \\
\hline 5 & 104 & 3.99 \\
\hline 6 & 121 & 4.80 \\
\hline 7 & 135 & 5.45 \\
\hline 8 & 147 & 6.02 \\
\hline 9 & 157 & 6.51 \\
\hline 10 & 166 & 6.92 \\
\hline 11 & 173 & 7.29 \\
\hline 12 & 181 & 7.65 \\
\hline 13 & 188 & 7.93 \\
\hline 14 & 194 & 8.29 \\
\hline 15 & 200 & 8.57 \\
\hline 16 & 206 & 8.85 \\
\hline 17 & 212 & 9.13 \\
\hline 18 & 217 & 9.38 \\
\hline 19 & 222 & 9.61 \\
\hline 20 & 227 & 9.85 \\
\hline
\end{tabular}




\section{Figure 1}

Average Shape of Futures Curves

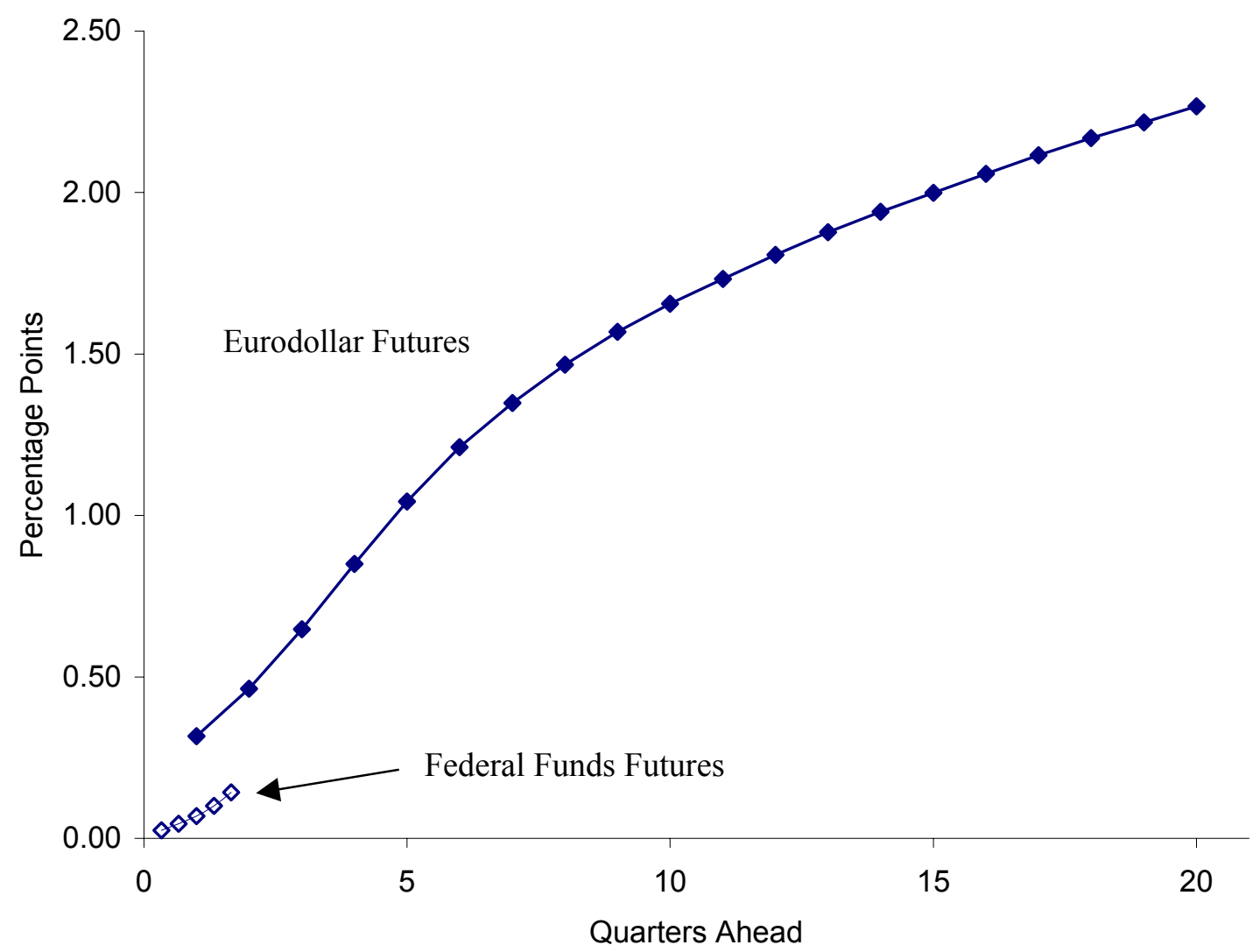

Average level of federal funds and eurodollar futures rates from 1992 to 2002 , expressed relative to the average level of the overnight federal funds rate. 
Figure 2

Expected Policy Path under Constant Risk Premium

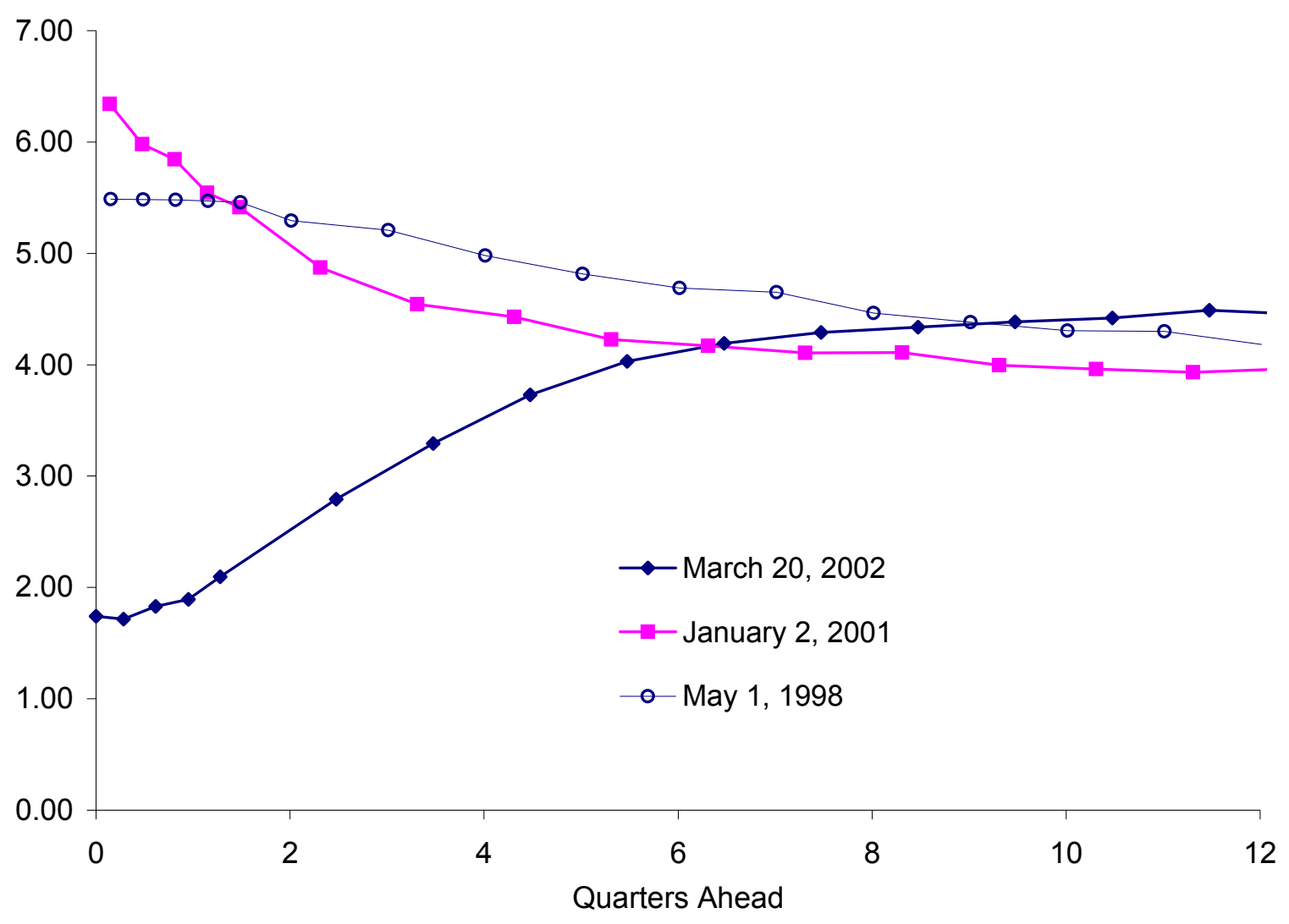


Figure 3

\section{Rates on Basis Swaps}

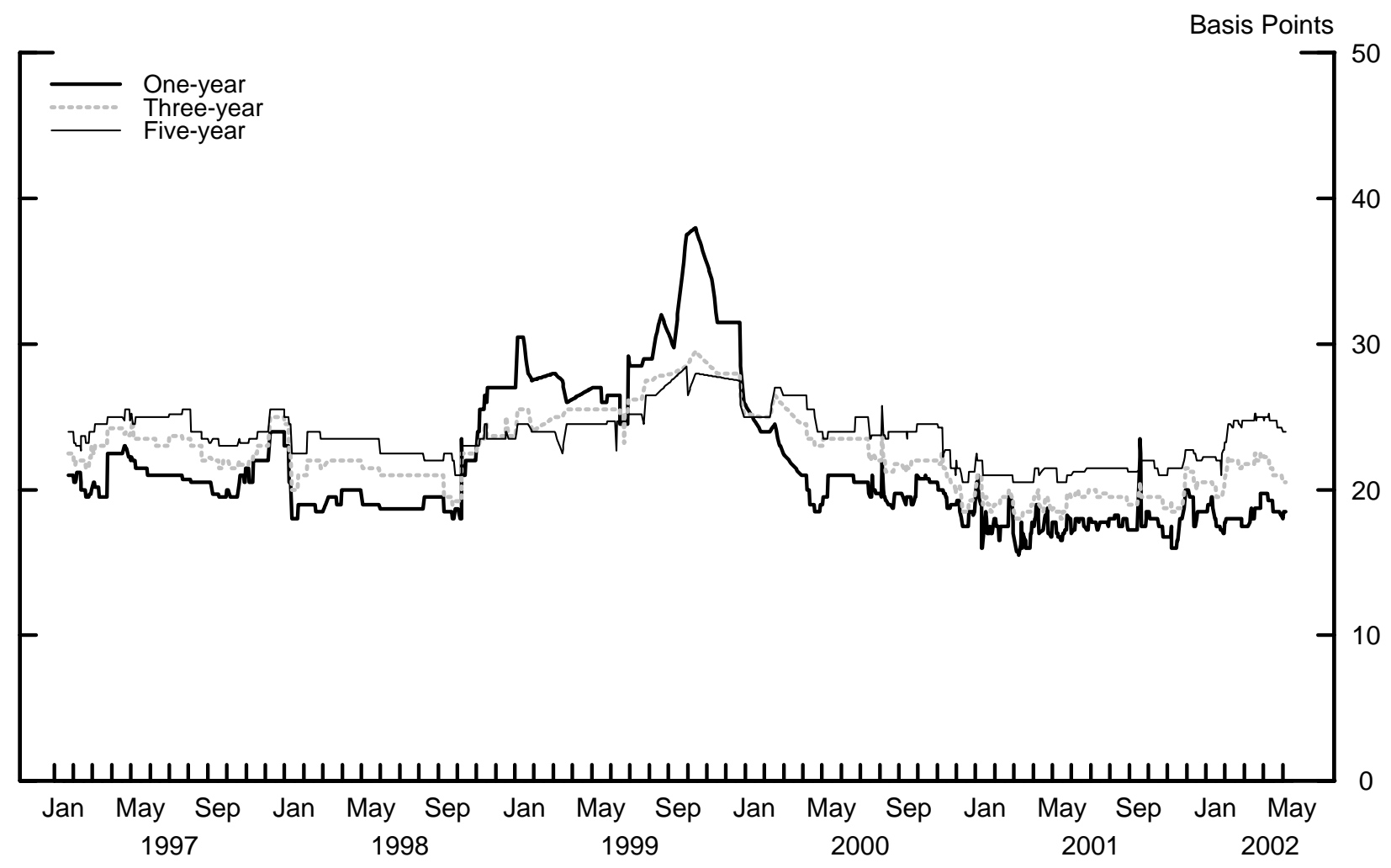


Figure 4

Term Structure of Eurodollar Futures Rates

March 20, 2002

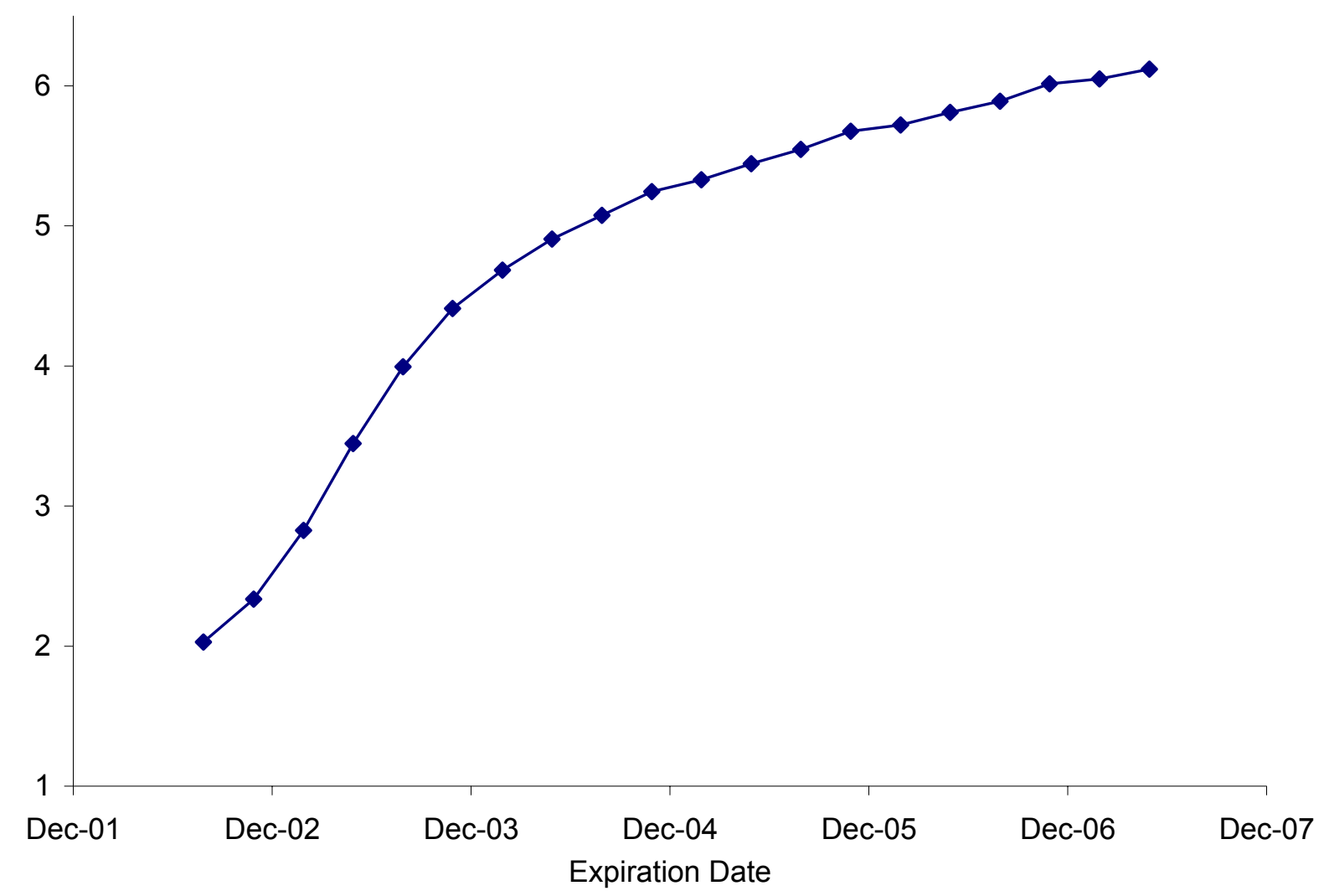


Figure 5

Term Premia Factor

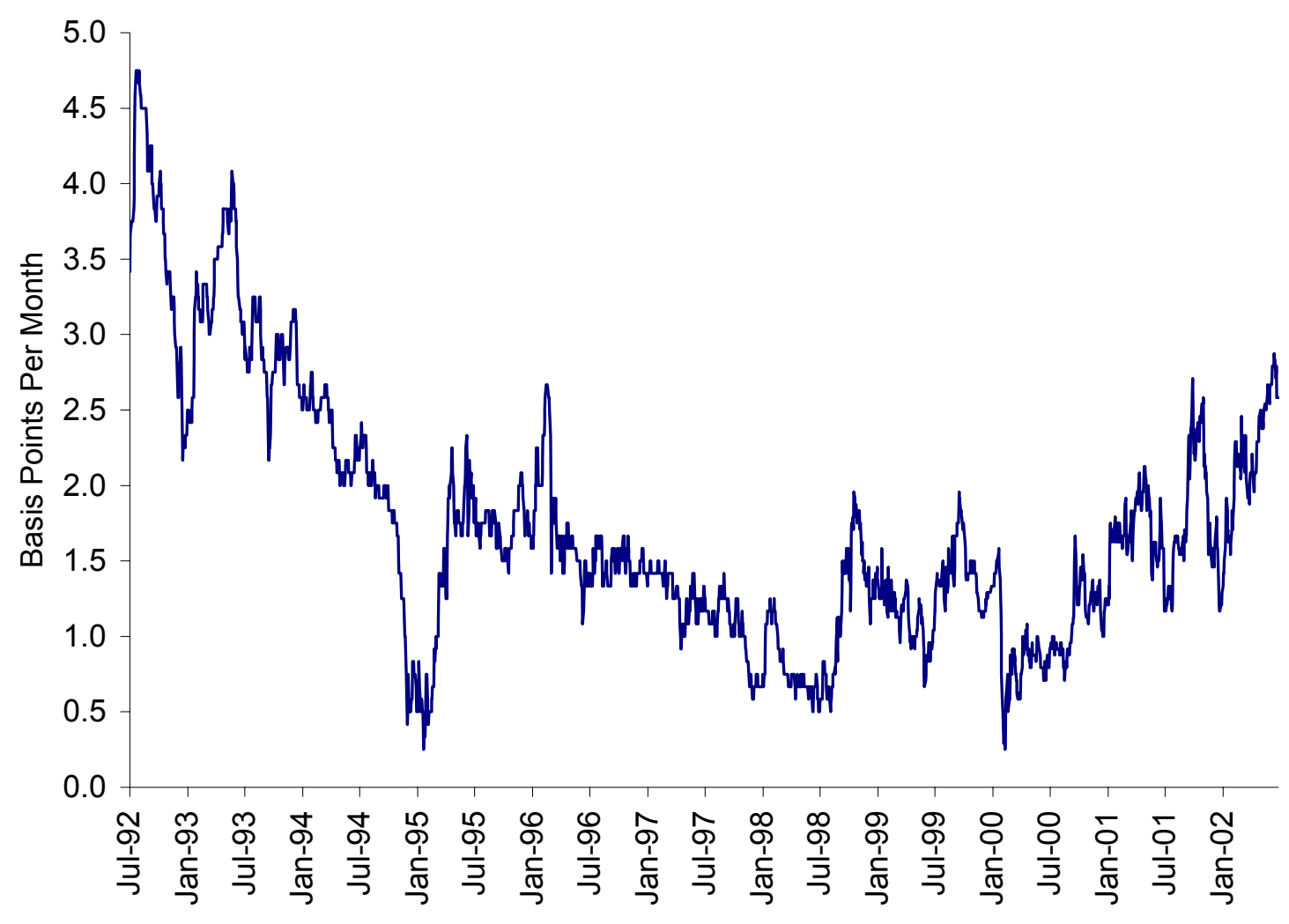


Figure 6

Policy Expectations Measure (7)

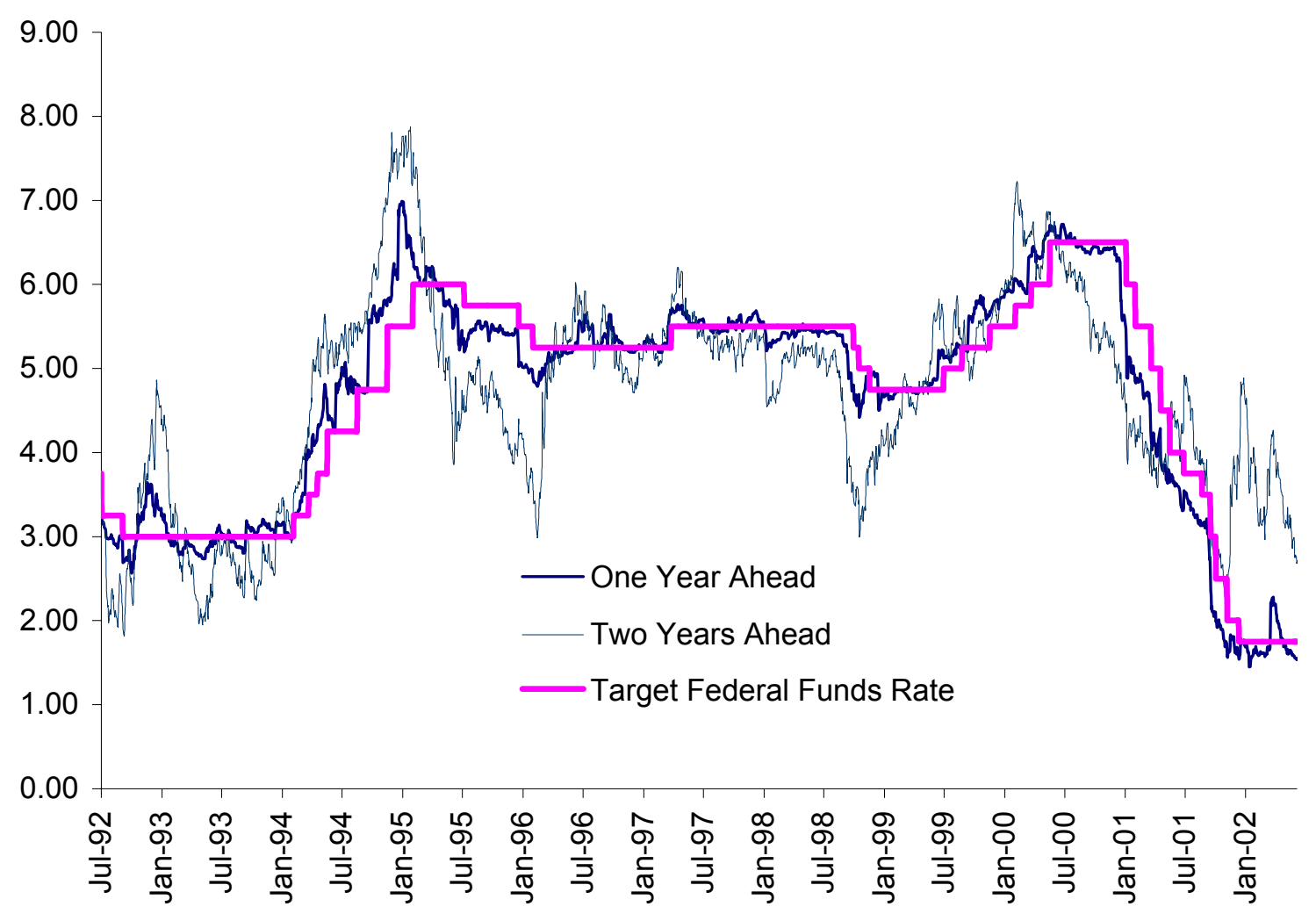


Figure 7

\section{Comparison of Policy Paths}

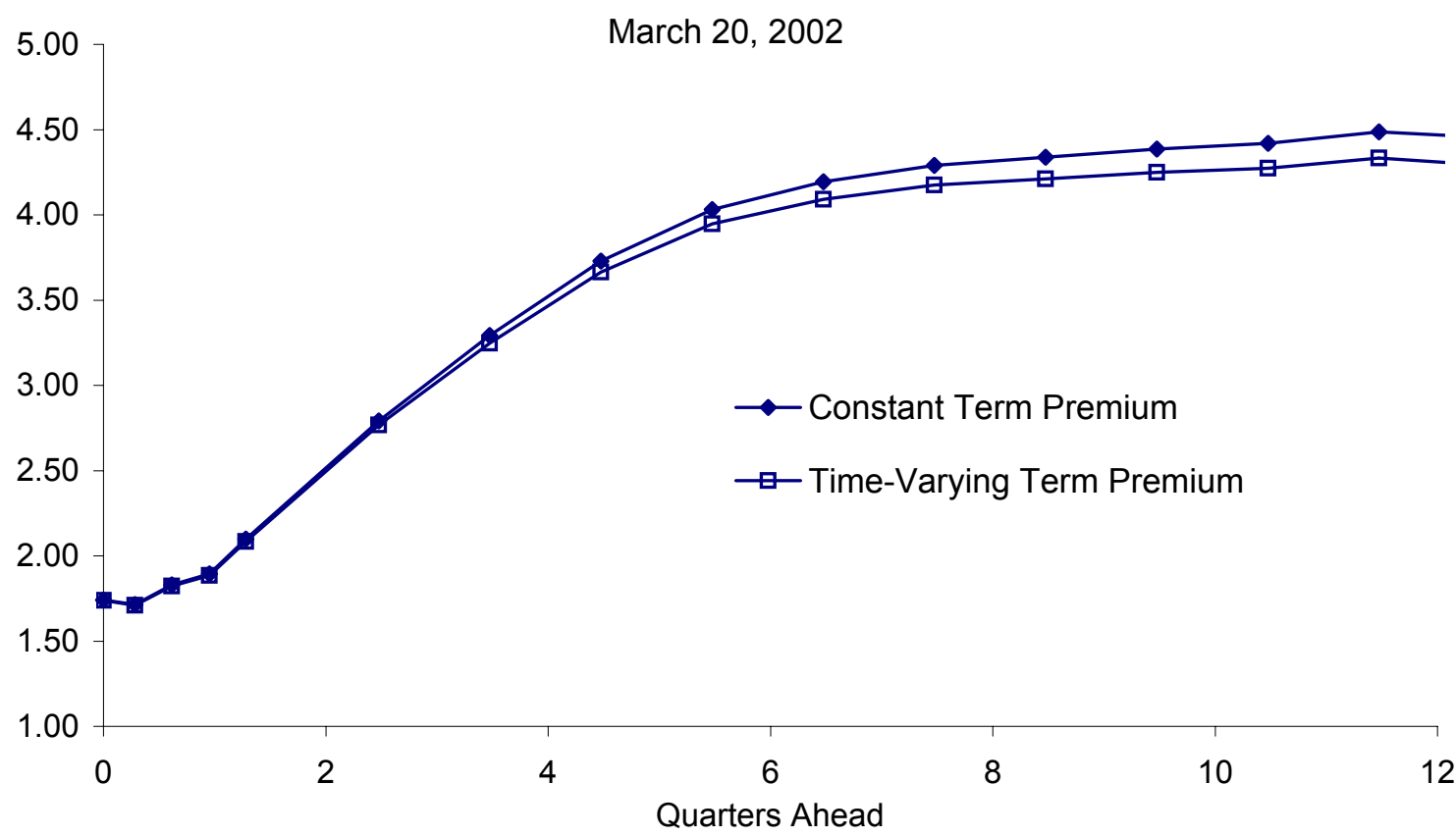

May 1,1998

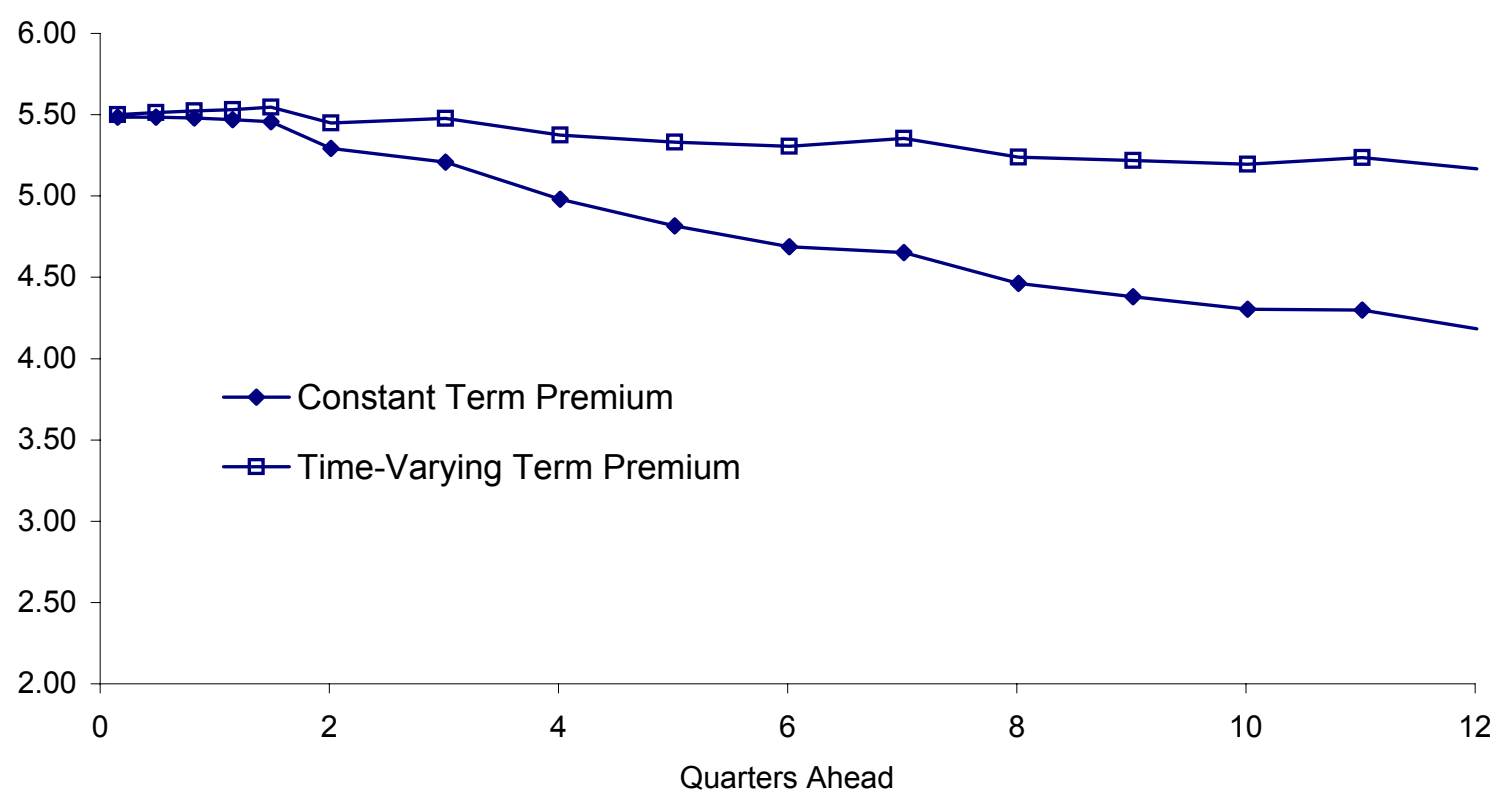


Figure 8

Policy Expectations Measure (8)

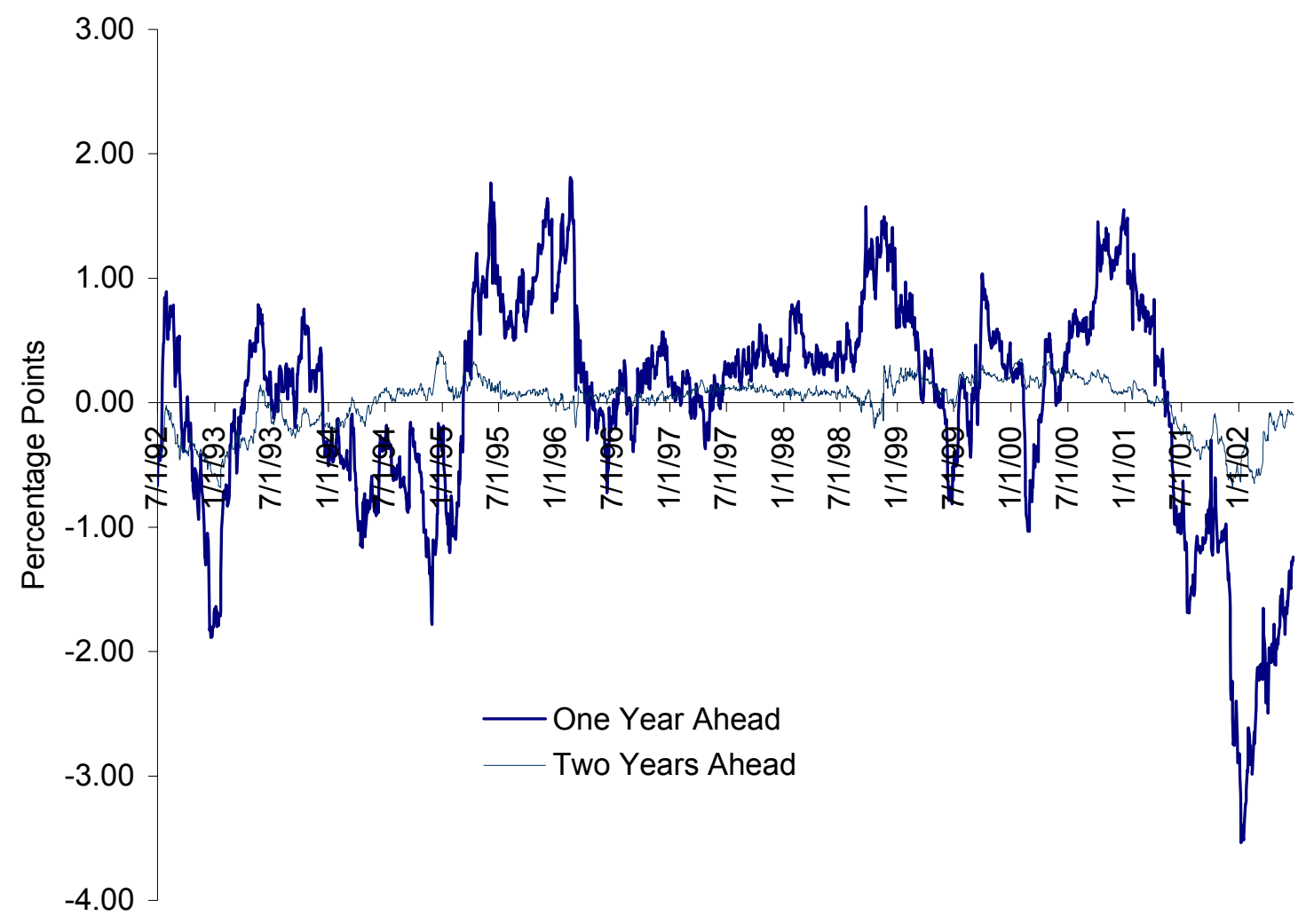


Figure 9

Measure (8) on Selected Dates

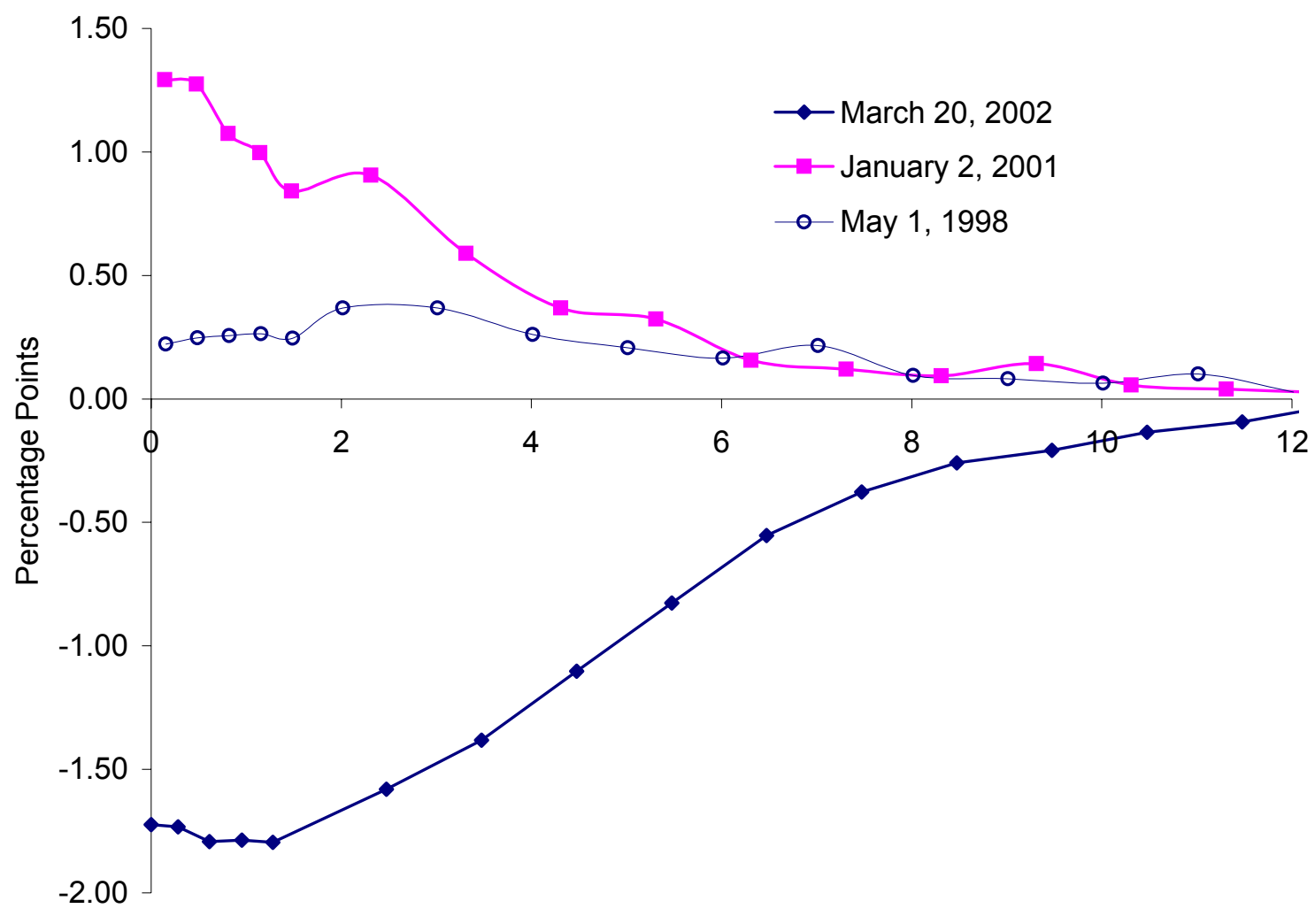

Quarters Ahead 
Figure 10

Standard Deviation of Daily Changes

January 1992 to June 2002

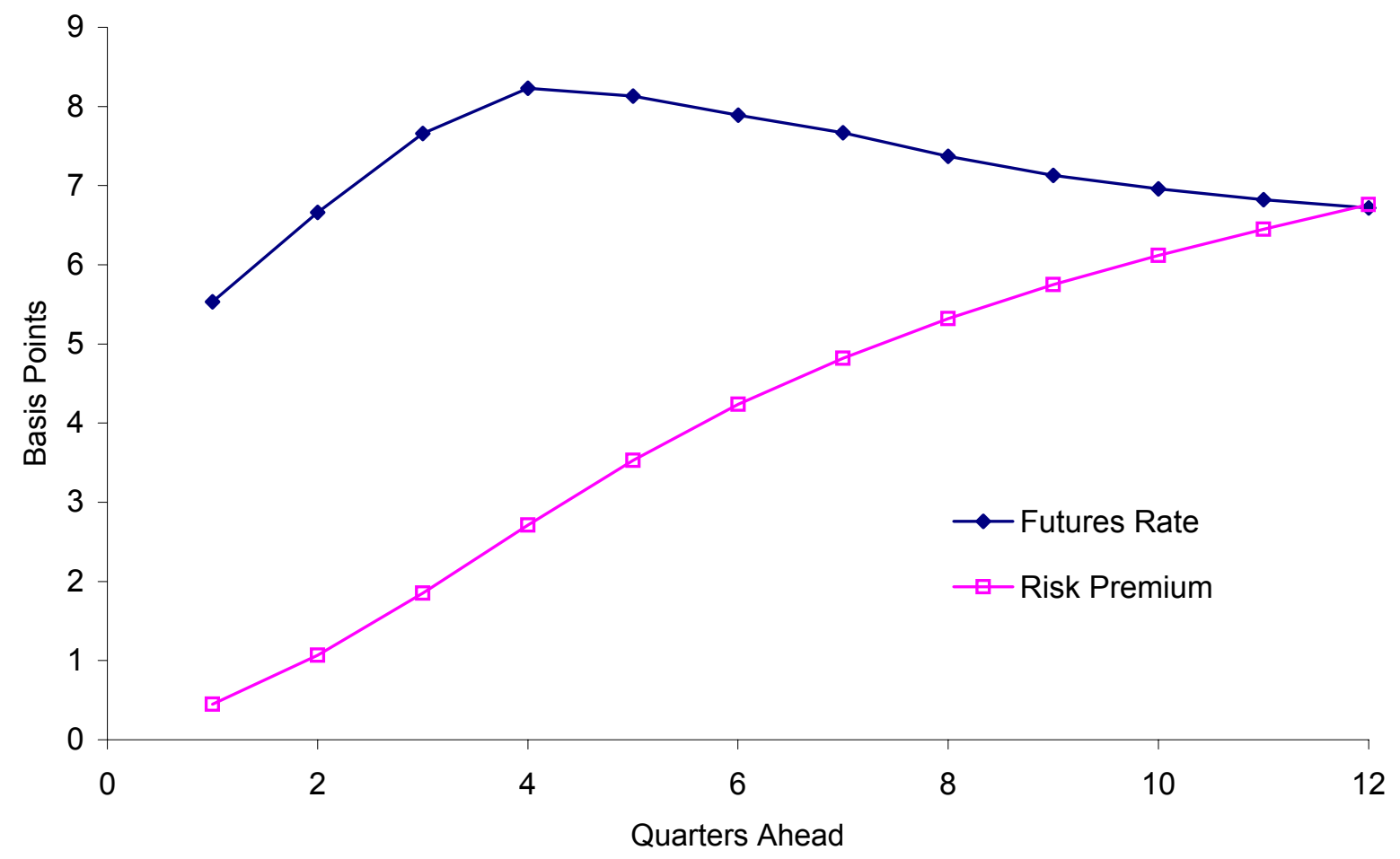

